\title{
Using Life History Calendars to Survey Vulnerability
}

\author{
Davide Morselli, Nora Dasoki, Rainer Gabriel, Jacques-Antoine Gauthier, \\ Julia Henke, and Jean-Marie Le Goff
}

\section{Vulnerability: The Ordinary Facet of Life}

European post-industrial societies are characterized by a high level of instability and fluctuation at economic, political and social levels (Crouch 1999). Hence at the turn of the twenty first century European countries are less stable than in previous historical periods (Sennett 2011). Confidence in the ability to keep social risks under control has been replaced by the idea that risks are not fully predictable or controllable. The side effect of such a change is a consequently greater exposure to risk factors that could force individuals to experience negative social and economical outcomes such as falling below the poverty threshold (Beck 1992).

The picture becomes more complicated than in previous (industrial) societies because new social risks emerge as the consequence of interactions between labour markets families and welfare systems producing a broad spectrum of negative outcomes (Ranci 2010). For instance the compensations for losses such as reintegration in the labour market after losing a job are not always effective in reducing social and psychological vulnerability and they perform differently for different segments

D. Morselli $(\triangle) \bullet$ J.-A. Gauthier • J.-M. Le Goff

NCCR LIVES, IP 201, Chavannes-près-Renens, Switzerland

Social Sciences Institute, University of Lausanne, Lausanne, Switzerland

e-mail: davide.morselli@unil.ch

N. Dasoki

NCCR LIVES, IP 213, Chavannes-près-Renens, Switzerland

Social Sciences Institute, University of Lausanne, Lausanne, Switzerland

R. Gabriel • J. Henke

NCCR LIVES, IP 213, Geneva, Switzerland

Centre for the Interdisciplinary Study of Gerontology and Vulnerability,

University of Geneva, Geneva, Switzerland 
of society. Negative outcomes must be framed in an analytical strategy that includes individual interpretations of the events in relation to their social and historical context on the one side and the personal and family history on the other. The interaction between the social context and individual life courses defines to a great extent the meaning and expectations individuals attach to life events.

In a context of uncertainty stability of the life course marked by a constant exposure to multidimensional risk factors, vulnerability is not only the possibility for an individual to experience a negative outcome or significant damage as a consequence of exposure to specific risk factors but also the lack of possibilities for individuals or social groups to activate protective and compensatory factors at different levels - material social and psychological. In other words vulnerability is not a state but a dynamic condition and can be defined as the time needed to recover from a negative outcome. Vulnerability is also multidimensional as it concerns simultaneously different aspects and dimensions of life their interactions in time and the interpretations given to them (Ranci and Magliavacca 2010).

Thus we can define social and psychological vulnerability as the difficulty to access resources to exit a particular negative and undesired state. This definition explains why the same risk factor may have different effects on different individuals (Ranci 2010). For this reason the study of vulnerability benefits from the adoption of a life course approach that accounts for multidimensional aspects of life and their interpretation. In this chapter we will focus on the life history calendar as a powerful tool for the study of multidimensional vulnerability.

\section{Life History Calendars: A Pragmatic Approach}

Researchers may use either prospective or retrospective methods to study lifehistories (Scott and Alwin 1998; Levy et al. 2005). Both methods have advantages and disadvantages. Researchers should therefore evaluate the method in relation to the research questions.

In prospective studies such as panels cohort studies and other longitudinal designs researchers maintain contact with participants over time and repeatedly interview them on their current conditions. The analyst reconstructs the respondents' life courses by looking at the answers given at the different observation points. The drawbacks of prospective studies would make the study of vulnerability across the whole life extremely difficult if not in some cases impossible.

By contrast in retrospective designs respondents are interviewed once to collect data on their past life courses. Retrospective methods are sometimes less efficient than longitudinal panels in which data are collected at precise intervals during the life course (Bidard 2010) because retrospective methods have to rely on the respondents' willingness and capability to disclose their past to the researcher; several factors may influence memory possibly leading to omission or misreporting of life events (Auriat 1996; Reimer 2001). 
Surveying a population requires some prior information to be able to design the sample. In the case of surveying vulnerability this would mean knowing beforehand who might potentially be in a vulnerable condition. Such priors are drawn from previous results and surveys that indicate which population strata are more at risk of being vulnerable and need particular attention.

For instance it is a common practice in birth cohort studies to oversample children from immigrant or low-income families. This approach produces high-quality data to investigate important issues concerning for instance inter-generational transmission of vulnerability. However it focuses on the life trajectories that have a vulnerable condition as their starting point but may fall short of capturing transitions into vulnerability. In addition while birth cohort studies can easily survey second-generation immigrants they provide poor information on the first generation. Collecting the same type of data on this population would require starting the study in a foreign country and monitoring the migration to the country of interest. Given these drawbacks it appears retrospective methods may be necessary to investigate certain research questions.

Starting from these considerations researchers have used different methods to minimize memory errors in surveys including decomposition (e.g. breaking a class of events into subclasses) the use of reversed chronological order the use of landmarks (e.g. transition points) and incrementing the time to answer survey questions (see Tourangeau 2000). Among these methods life history calendars (LHCs) seem to perform particularly well because they enhance several aspects of memory retrieval (Caspi et al. 1996; Freedman et al. 1988). The LHC is typically a two-way grid with the temporal dimension on one side and different life domains (e.g. residence family employment) on the other. Respondents report events for each life domain relating them to what happened in other life domains or to other time markers. With LHCs respondents can visualize their life trajectory linking what happened to when where it happened and for how long it lasted. Thus the calendar tools facilitate respondents' ability to place events into a temporal context by relating them to other synchronic (parallel) or diachronic (hierarchical) events and episodes that occurred in the life span (Belli 1998).

Researchers have produced a large corpus of evidence in the last 30 years comparing the quality of data obtained with LHCs and conventional questionnaires. For instance Becker and Sosa (1992) showed the LHC resulted in more consistent reports (i.e. less superposition of mutually exclusive behaviours) than the conventional questionnaire. Goldman et al. (1989) and Yoshihama et al. (2005) argued that the calendar was more effective in enhancing the recall and reporting of specific events (e.g. contraceptive use domestic violence victimization). Engel et al. (2001a) suggested that the LHC performed better than the traditional question-list in terms of completeness. The visual nature of the calendar makes it easier for the interviewee and the interviewer to spot incongruous answers in the data reducing the unaccounted for amount of time in the respondent's life course. Test-retest reliability studies showed very high agreement for reported life events such as marriages and migrations (Engel et al. 2001b). 
In addition to these indirect evaluations some experimental comparisons between calendar instruments and conventional questionnaires showed that adding a timeline to the questionnaire enhanced data quality in comparison to the regular questionnaire procedure (Van der Vaart 2004). Similarly Belli et al. (2001) showed that the calendar produced lower levels of reporting error than conventional question lists concerning the number of residential moves income weeks unemployed and illness but it over-reported history of cohabitation and number of jobs.

Why do LHCs help to report retrospective data? According to Conway (1992, 1996) autobiographical memory is a non-linear process that works through different association mechanisms. Events can be recalled through their hierarchy (e.g. from more important to least important) through their sequence (e.g. in chronological order) or in relation to other events and episodes. In addition different individuals may be more comfortable or used to recollecting events in different ways. Thus Belli (1998) argued that the calendar facilitates the use of all three memory retrieval mechanisms as well as facilitating a flexible interaction between the respondent and the interviewer to clarify intended meanings and to reconstruct the past.

In line with these assumptions Glasner (2011) compared the number of edits (i.e. corrections) by respondents who answered the same questions in an online conventional biographical questionnaire as compared to an online LHC. Congruently with Belli's rationale but without the interviewer/respondent interaction Glasner found the number of edits in the calendar mode were twice as high as those in the conventional questionnaire. In other words respondents were more likely to correct and improve the quality of biographical calendar data by respondents than conventional questionnaire data.

Consistent with this results from cognitive interviews conducted at the Swiss National Centre of Competence in Research LIVES with respondents aged 35-66 with medium to low levels of education showed that in seven out of ten interviews the calendar structure encouraged respondents to re-edit their answers concerning several life domains (residence cohabitation couple relationships family work and education health other unexpected events). During the cognitive interviews the sequence through which respondents completed a self-administered calendar was recorded by an external observer.

Table 1 reports the sequence used by the respondents to fill in the different columns of the calendar (ordered from $\mathrm{A}=$ residence to $\mathrm{G}=$ other unexpected events). In the most linear sequence (Type 1) three out of ten respondents filled the columns of the calendar in order starting from the first one on the left (residence) then passing to the second (cohabitation) and so on until they reached the last one on the right (column 7 other unexpected events).

Type 2 respondents (three out of ten) completed the calendar in sequential order except for the first two columns (residence and cohabitation). They used residence and cohabitation as anchors for recollecting the changes in both domains. Once these two columns were properly completed respondents went through the rest of the calendar in an almost linear manner from columns 3 to 7 . Type 3 respondents (four out of ten) completed the task in a less sequential order using the information of certain columns to step back and make changes in the previous data. 
Table 1 Sequence of the edits for each column during the LIVES cognitive interviews

\begin{tabular}{l|l|l|l|l|l|l|l|l|l|l|l|l|l|l|l}
\hline Type of respondents by editing style & \multicolumn{10}{ll}{ Editing sequence } \\
\hline Type 1 respondents & A & B & C & D & E & F & G & & & & & & & & \\
\hline & A & B & C & D & E & F & G & & & & & & & & \\
\hline & A & B & C & D & E & F & G & & & & & & & & \\
\hline Type 2 respondents & A & B & C & B & A & C & D & E & F & G & F & G & F & & \\
\hline & A & B & C & B & A & B & A & B & A & B & C & D & E & F & G \\
\hline & A & B & C & B & A & B & C & D & E & F & G & & & & \\
\hline Type 3 respondents & A & B & C & D & E & F & E & G & & & & & & & \\
\hline & A & B & C & D & A & B & D & E & F & G & & & & & \\
\hline & A & B & C & D & E & F & G & E & F & B & G & & & & \\
\hline & A & B & C & G & D & E & E & B & C & E & F & D & E & & \\
\hline
\end{tabular}

$\mathrm{A}=$ residence $\mathrm{B}=$ cohabitation $\mathrm{C}=$ couple relationships $\mathrm{D}=$ family $\mathrm{E}=$ work and education $\mathrm{F}=$ health $\mathrm{G}=$ other unexpected events

While the Type 1 respondents did not re-edit the information they had reported the graphical and conceptual structure of the calendar helped Type 2 and 3 respondents to retrieve and report autobiographical memories. Without the calendar Type 2 respondents may have had more difficulties in accurately recalling their residence and cohabitation history and Type 3 respondents may not have gone back and corrected the information they had reported previously.

Auriat (1993) argued that when people are asked to remember episodes in a sequential order misdating a certain point of the sequence is likely to produce errors in reporting the subsequent events. Thus the calendar methods may decrease distortion by forcing respondents to visualize the sequence and anchor it to surrounding events (as with the Type 2 respondents). Cross-referencing between life events becomes then a resource that can be used by the respondent but also by the interviewer. The calendar format facilitates the interaction between interviewer and respondent in face-to-face interviews leading to a more precise check of the reported information (Belli et al. 2001; Sutton et al. 2011). Engel and colleagues (2001b) compared the calendar method to a self-reporting questionnaire and concluded that people are more willing to provide correct information and are more cooperative during the administration of LHCs.

\section{Memory Bias as a Hidden Resource for Understanding Life Histories}

So far we have discussed how LHCs help to reduce the probability of memory biases and misreporting of dates. A provocative alternative approach is not to consider errors as a problem for data analysis but as an important source of information in their own right. According to Couppié and Demazière (1995) memory errors are not distributed at random but depend on specific social variables that may be connected 
to the phenomenon under investigation. From a sociological perspective memory is not a simple restoration or reproduction of the past but a reconstruction of the life trajectory; this partly depends on the situation respondents are in when asked to recollect information on their experiences (Halbwachs 1994[1925]).

For Halbwachs the recollection of events is the result of two interrelated thinking strategies. The first consists of "locating" an event in its social context in terms of time and space. Like some sort of time travel people progressively place themselves in a frame that facilitates the recollection of personal events. In the second mnemonic process people transfer their focus from one single event to another focusing on its nature and its meaning (Halbwachs 1994 p. 201).

The meaning of what is recollected has a social frame that depends at the same time on the different social groups the participant was a member of when a particular event occurred and on the social groups the participant belongs to at present. Coenen-Huther (1994) mentioned for instance that reports of past events differ according to the respondents' gender age or social class. In the case of gender she argued that women tend to structure their memory according to family events while men structure their memory in relation to the professional domain.

In Halbwachs' perspective some events and objects fade from memory because they are no longer meaningful if related to a social frame that no longer exists. For example when a specific social group to which the respondent belonged no longer exists at the moment of the interview the respondent is more likely to omit events experienced in relation to that group or situation. Such omissions are therefore not due to the fact that the events were not important in the past but because they are no longer relevant at the time of the interview.

A comparison of two life events calendars completed by the same respondents the first completed 5 years after they left school and the second one completed 9 years later showed some time differences in the job history (Couppié and Demazière 1995). For example respondents were more likely to omit precarious jobs and short spells of unemployment in the second wave if the respondents had been employed in a permanent position between the two waves. Memory is therefore a dynamic process which generates information reconstructs life events and attributes meaning according to both current and past conditions.

Answering retrospective biographical questionnaires as with any autobiographical process is thus not only a means to provide information on social phenomena but also represents processes of social construction that attach meanings to questions and answers. When respondents use biographical memory to communicate life events and experiences to others (e.g. an interviewer) they organize their memory in an ordered and coherent way in which casual and unexpected events may take on a coherent (and sometimes causal) structure (Bertaux 1981; Ricoeur 1985). The respondent becomes the author of a narrative in which he or she is the main character attributing a sense of coherence to his or her life. In other words in the autobiographical narrative respondents order their life events into a matrix that is culturally and socially constructed and gives sense and meaning to what happened (Bruner and Weisser 1991). 
The structure of a LHC in particular serves as a standardized grid that helps respondents report their life trajectories and assists researchers in framing the data. However the choice of standardization and the type of information requested are bound to interact with the respondents' reconstruction of their lives. They obligate respondents to re-organize their lives in a certain way; the reported information is therefore shaped by this constraint. The biographical questionnaire forces respondents to elaborate a socially-constructed theory of their lives. Respondents have to select the events to report among the wide range of their life events. They do so in relation to the type of events requested and the way the questions are formulated. In this process they sort the events giving them different importance and different priorities. They then order the events following the logic of the questionnaire (e.g. chronological). Thus responding to a biographical questionnaire such as the LHC is a social action. Respondents use life events to tell a story (with all its meanings and implications) to someone: the interviewer, the research project, the scientific world or the social and political environment (Bruner 1990; Eco 1984).

Taking these aspects into account to analyze social events and survey data can open the door to new and multi-faceted insights and the analysis of LHC data is particularly interesting in this respect. Embarking in this direction a scientific paradigm that considers autobiographical narratives in terms of self-construction is needed (Bruner 1990; Ricoeur 1985). This type of approach is not new to the hermeneutic and phenomenological traditions which are commonly based on a relatively small sample or single case analysis. In contrast LHCs are the junction between autobiographical narrative and quantitative data and they can be used in large-scale surveys. LHCs produce biographical data that are at the same time narrative and quantitative and for this reason they are useful for analysis using either qualitative or quantitative paradigms. Introducing LHCs into survey designs can therefore extend the hermeneutic approach to investigate large populations superimposing constructivist and positivist paradigms.

For example Couppié and Demazière (1995) showed that the absence of reported unemployment episodes is strongly influenced by the way the category "unemployment" is defined in the calendar and by the current occupational status (employed or unemployed) of the respondents at the time of the interview. Instead of considering discrepancies in the data or misreporting as errors the authors analysed the missing information as a dependent variable. In other words they treated non-response as a way of answering the question that indicates a specific process of social integration (Bourdieu 1979). Researchers can estimate the size of non-response by comparison with other studies or subsamples with lower missing values and cross that information with other socio-demographic indicators to estimate whether the missing data are random. However the risk of this approach is to link results to a particular context and setting undermining the generalisation of the results. Using a similar approach Couppié and Demazière proposed replacing the notion of memory error (or memory bias) which implies a fault in the data with the notion of memory deviation stressing the process of social construction of the reported information. This research approach is intriguing in many ways but largely unexplored in survey research. 
In summary LHC methods not only perform better than conventional questionnaires in collecting retrospective data but also serve as a tool for different scientific paradigms. Researchers can use LHCs to investigate how people interpret and define the social world and their self-positioning within it. LHCs allow researchers to account for the interaction between events (objective/factual data) and their interpretation (subjective/perceived factors) in different life domains.

As noted earlier this approach is close to the phenomenological perspective in which the interactions between people the social world and cognitive processes are the objects of investigation (Gadamer 1975; Fisher 2004). How people interpret facts and why they formulate certain interpretations instead of others is central in the phenomenological approach. According to Schutz (1962) people structure their lives in socially defined life spheres that are interconnected and interact with each other. The life spheres are structured in a hierarchy in which some are more important than others for both individual and social reasons. The interaction between the life spheres shapes the meaning attributed to life events. When things happen which specific life spheres are involved and the way the life spheres are interconnected with each other are all elements that structure individuals' interpretation of their lives and different reactions to the same life events.

\section{Using a Life History Calendar to Survey Vulnerability}

We defined vulnerability as a dynamic and pervasive process embedded within social life. In this chapter we focus on three interrelated processes of vulnerability: diffusion accumulation and interpretation. The process of diffusion is based on Schutz's (1962) definition of life spheres according to which an individual life is categorized into different domains-e.g. family work social relations political life and so on. The definition of each sphere is socially constructed and as we discussed the way researchers define each sphere in designing questionnaires or LHCs is charged with meanings.

Nevertheless each sphere can be the object of specific disciplinary investigations given that the notion of a sphere itself presumes that life spheres are independent of each other to some extent. However they are not completely independent; both positive and negative spill-overs may occur. For instance events that happen within the family life can influence the work sphere or social relations. Experiencing a divorce can strongly affect the network of interpersonal relations of the two ex-partners (Widmer 2010). Accounting simultaneously for different life domains allows researchers to study spill-over effects with LHCs.

In addition as life spheres are framed as interdependent interdisciplinary research is needed. The LHC tool is particularly suitable for multi-disciplinary research because it produces a relatively large amount of data suitable for analysis from different perspectives (demography sociology psychology social-psychology and more).

Besides diffusion processes the interaction among events that happen within each life-sphere is also fundamental for understanding vulnerability. The accumulation of disadvantages including the temporal distance between negative and positive 
outcomes as well their sequence can put people in a severe condition of risk affecting the reconstruction of resources needed to exit from vulnerability (Dannefer 2003, 2009). The temporal structure of LHC data is particularly suitable for accounting for these aspects and can be used for performing sequence analysis event-history analysis or other longitudinal models (Axinn and Barber 2001; Axinn et al. 1999).

Last but not least the interpretation of events is at the same time a dependent and an independent variable in the study of vulnerability. The same event can assume very different meanings and affect peoples' lives in very different ways. For instance members of different social classes or members of the same class may not experience losing a job or being fired in the same way. Thus an event that for one person can start a dangerous domino effect may be a minor problem for another person.

In addition the meaning attached to events is culturally and socially embedded. Losing a job in a period of economic crisis may be a different experience compared to losing it in a period of economic growth. On the other hand in a period of crisis the loss of the job becomes sadly common while in other historical periods it could represent a less likely and for this reason more stigmatizing experience (Oesch and Lipps 2012). The interpretation of events and their relationships with the socialhistorical contexts are tightly related and researchers can address them both easily in two ways with LHCs.

Data in LHCs are both connected to temporal-i.e. the year in which events occurred - and spatial dimension-i.e. where the respondent was located at the time the event occurred. This makes it possible to relate events to places and consequently to social and historical contexts. In addition LHCs can allow a retrospective evaluation of events providing information on individual interpretations of life trajectories. This is probably one of the less developed uses of LHCs although it is central to the study of vulnerability. In the next section we present some experiences with using LHCs to tap the three processes of diffusion accumulation and interpretation as examples of the use of LHCs to survey vulnerability.

\section{Designing Live History Calendars for Research on Vulnerability}

\subsection{The 'Devenir Parent' Survey}

The Devenir Parent ${ }^{1}$ [Becoming a Parent] survey was conducted between November 2005 and May 2009 by an interdisciplinary team from the universities of Lausanne and Geneva. The aim was to investigate the factors of differentiation in professional trajectories between men and women during the transition to parenthood in contemporary Switzerland (Le Goff and Levy 2011). The Swiss welfare system

\footnotetext{
${ }^{1}$ Swiss National Science Foundation grants no 100012-109692/1 100012-113598/1 100012115928/1 and 100017_130233/1.
} 
lacks adequate childcare infrastructures (OFS 2008) and women risk being forced to abruptly change their professional careers because of the impossibility of leaving their child in day care (e.g. Le Goff 2005). Thus after the birth of the first child one partner-often the woman - may be forced to diminish working hours or to resign from her job with evident repercussions for the household economy and equality between partners.

The Devenir Parent survey was a three-wave panel: 235 Swiss-French couples volunteered for three interviews, the first during the second half of the pregnancy, the second 4-6 months after childbirth and the third a year later. Researchers asked questions on the redefinition of personal identity social roles everyday life professional activities family and friendship networks in face-to-face interviews conducted separately with both partners. The researchers also conducted in-depth qualitative interviews.

In the third wave the participants filled out two LHCs. The first retraced events in different life domains from the age of 15; the second focused on the professional trajectory from the moment of conception to the year after childbirth. This short calendar tapped periods of non-activity due to maternity leaves as well as from unemployment and other possible reasons. In the case of women the calendar also traced childcare trajectories with details about the type of care and the average duration per week. Although this calendar focused on factual data it allowed researchers to connect events to subjective expectations and intentions as formulated in the first and second waves and eventually in qualitative interviews.

Figure 1 displays the story of a woman "Annette" (a fictitious name) in the months following the conception of her first child. In the first wave Annette mentioned she was working full-time but she had intended to convert her contract to a half-time job after the maternity leave. She also declared that her employer did not agree to restructuring the contract and she expressed her intention to change jobs. During the first interview Annette mentioned an intention of leaving the child at a nursery five half-days a week which corresponded to a $50 \%$ part-time job. At the time of this first wave she was still waiting for an answer from the nursery.

The LHC questionnaire showed the uncertainties related to these two intentions and more deeply some vulnerable dimensions linked to the transition to parenthood. At the end of her maternity leave which in the Swiss canton of Geneva where Annette lived was a maximum of 4 months the lack of an available place at the day nursery made it impossible for Annette to register at the unemployment office because an administrative Swiss rule stated that a person can be considered unemployed only if he or she is immediately available to take a job. Because the child could not be left unsupervised Annette could not be considered available and therefore "unemployed." She was forced to take unpaid leave until a place in the nursery became available 4 months later.

Eventually the nursery accepted the child for five half-days a week. Annette could then look for new employment. After three more months she began a $50 \%$ parttime job. During all this period her husband worked full-time as a manager of an administrative department in a corporation. The story had a happy ending with the situation fulfilling the initial intentions about work and childcare. 


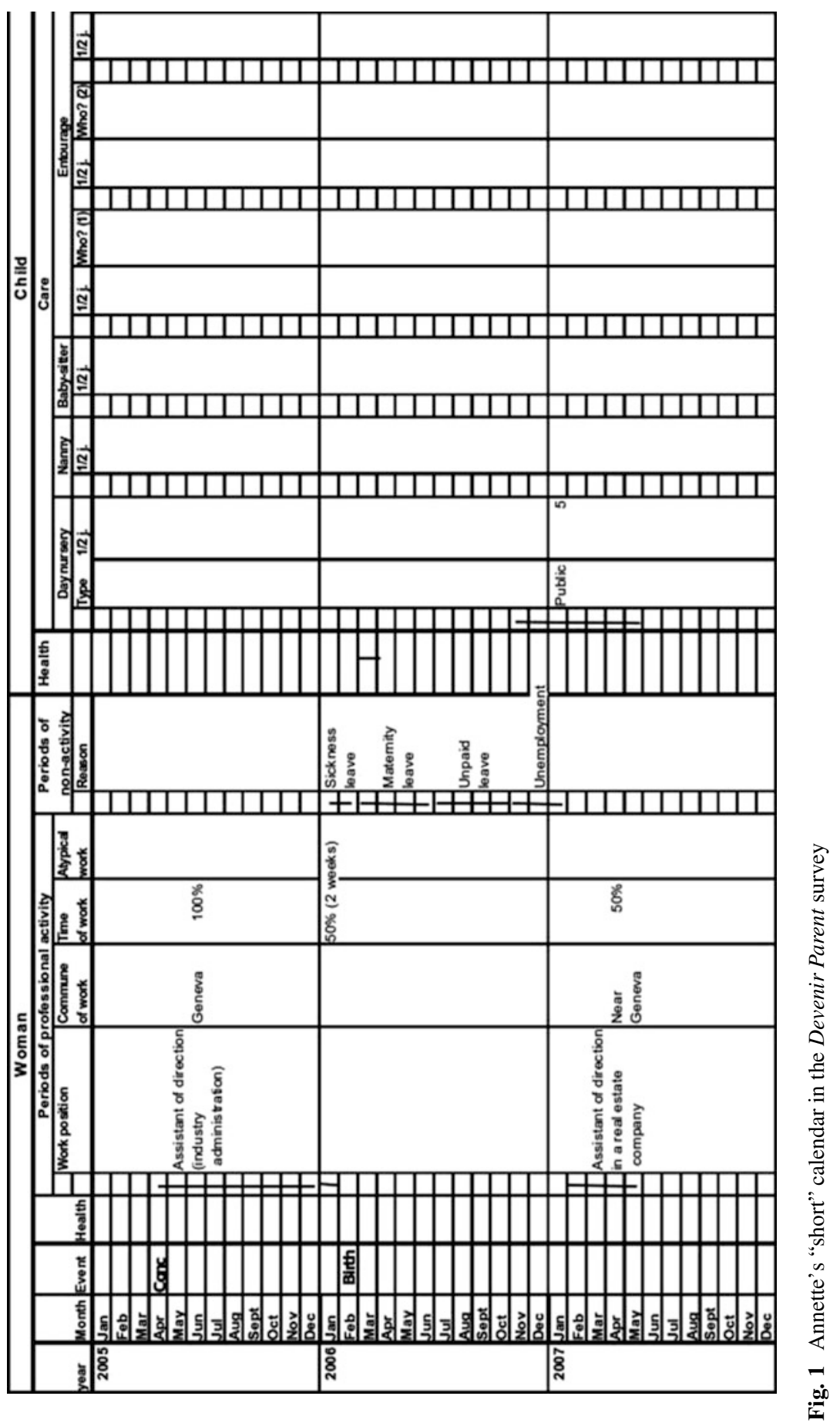


However Annette was exposed to social risk in two regards: the first related to the necessity to end her first job; the second related to the non-availability of a place in the day nursery at the end of the maternity leave. If she had not found a new job or if the unavailability of childcare would have been longer the vulnerability of her situation would have been more serious. The initial expectations would not have been fulfilled creating a potential situation of psychological distress as well as a redefinition of the household economy and family roles. In the months preceding the important social transition of becoming a parent the partners project themselves in the future with baggage full of personal and social norms. We thus speak of the birth of the first child as a normative event that generates a series of expectations and plans. When these expectations are not fulfilled the potential for parents to experience negative outcomes and remain constrained by the situation is greater. Unexpected events may have significant consequences.

The Devenir Parent LHC constrained individuals' life trajectories into sequences of events concerning two life domains: employment and childcare. Thus the analysis of the LHC alone does not indicate what happened outside these parameters. The LHC in the Devenir Parent was only one part of a more complex survey. A different approach would be to use the LHC to directly collect data on unexpected or unwanted events in each of the life domains. The next example shows how life calendars can be used to tap non-normative (i.e. unexpected) critical events.

\subsection{Family tiMes}

Two cohorts of 400 individuals born in 1950-1955 and 1970-1975 and drawn from a representative sample of the Swiss population participated in the Family tiMes $^{2}$ survey. Like Devenir Parent but not concerned with the specific transition to parenthood this survey was also aimed at capturing from a life course perspective the changing web of constraints and opportunities in which family and occupational trajectories of individuals unfold. Besides questions on values and opinions and an instrument measuring the personal networks of relationships (Widmer 2010) that were recorded with computer-assisted personal interview (CAPI) mode the Family tiMes survey included a LHC (Fig. 2) designed to be hetero-administered by means of a paper questionnaire in a face-to-face interview setting.

The calendar brought together six life domains (cohabitation residence intimate relationships occupational activities and critical life events) with 6-month time units. On this basis the researchers asked respondents to mention information on what happened in each domain and for how long indicating the beginning and the end of each episode.

Concerning residence the calendar recorded the number of moves as well as the corresponding destination area code (even for changes within the same area). For intimate relationships longer than 3 months respondents identified each partner

${ }^{2}$ Swiss National Science Foundation grants no 100017_130343/1. 


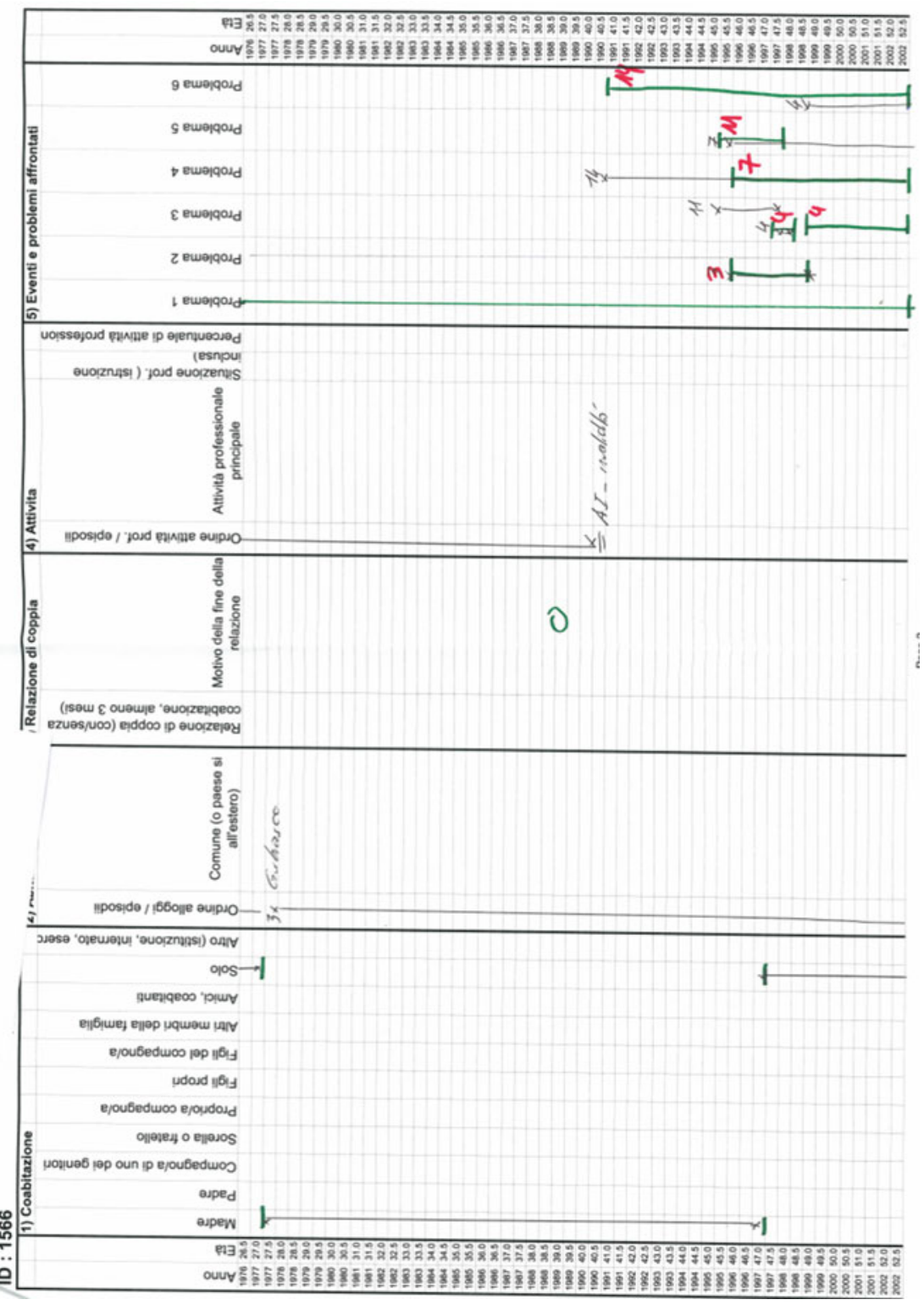


and recorded the reasons for separation. The LHC also included inquiries into the number of jobs type status and activity rates to tap occupational careers.

In addition to these events the last part of the calendar was dedicated to nonnormative and unexpected critical events. The survey asked respondents to indicate up to a maximum of six simultaneous critical events (e.g. serious accident or illness depression severe conflict long unemployment period) relative to themselves or one of their close relatives. Non-normative events have cumulative properties and are systemically associated - as dependent independent or intervening variables - with dysfunctions in other life domains (e.g. Hill 1958). On the other hand these types of events may be more susceptible to being misreported in conventional retrospective interviews.

In conventional questionnaires the interviewing sequence may affect the likelihood of reporting non-normative events with respondents' recollections of more recent events impairing their ability to remember earlier occurrences (Belli et al. 1997). By contrast in LHCs the iterative structure of the interview and the use of temporal landmarks help the respondents access and report memories on unexpected events (Yoshihama et al. 2005). Thus LHCs seem particularly useful in collecting data on vulnerability factors and their cumulation.

Inspired by the French Ageven tradition (Vivier 2006; Antoine and Lelievre 2009) and in line with the life course paradigm (e.g. Mortimer and Shanahan 2003) the Family tiMes calendar focused on individual trajectories as produced by an events-related logic rather than by an underlying generative process. It aimed at explaining a trajectory through the chronological order of events and the social statuses linked to it. This process is supposed to be multidimensional. In this sense it is the result of a double interaction: one synchronic (level of normativity/compatibility between various statuses at a given time point) the other diachronic (the kind of path dependencies resulting from antecedent configurations). In this holistic perspective researchers can display and eventually explain patterns of linked trajectories.

The face value of the filled calendars confirms the above statements as relational features (absence or multiplicity of partners divorce and separation) are associated with the occurrence of problems. Sometimes residential mobility solo living and unstable intimate relationships are characteristic of a trajectory. Parental separation childbirth and chronic illness often appear synchronically or diachronically together. Such interrelated mechanisms are visible in the example (Fig. 2). In this case the respondent suffered from chronic conditions: at age 20 his father and sister died in an accident reducing his social resources to his mother. After a period of relative stability the death of his mother associated with his unemployability left him completely isolated facing financial difficulties and depression.

The combination between the four life domains (cohabitation residence intimate relationships and occupational activities) and the non-normative critical events returns a complex — not simplistic — and holistic picture of individual life courses. In Family tiMes the critical life events were unexpected problems that respondents had to face during their life histories. As discussed above the weight for the personal trajectory derives from the (synchronic) interaction of life domains and 
by the (diachronic) accumulation of negative critical events. However this approach assumes that certain types of events may be generally understood as advantages or disadvantages. This may not always be the case and some events that can be disruptive for certain individuals or social categories may have a different weight for others. Thus the subjective interpretation of events assumes an important role in understanding the incidence of events on life histories. The next two examples illustrate the use of LHCs to assess subjective evaluations of trajectories.

\subsection{Vivre/Leben/Vivere and the Swiss Panel LIVES Calendar}

The Vivre/Leben/Vivere (VLV) survey $^{3}$ on the health and living conditions of the elderly population in Switzerland implemented another LHC. The aim of this choice was to collect retrospective data on the respondents' life trajectories but also to help the target population of individuals aged 65 and older with memory recall through the graphical visualization of their life histories. In addition the VLV calendar aimed to collect retrospective evaluations of respondents' life trajectories.

The VLV calendar was self-administered and later checked by an interviewer by means of a CAPI protocol to correct or complete information if necessary when unclear or incoherent. It included five life domains: residence family and relationships job health and nationality. Because the calendar was self-administered it also provided general guidelines on the type of events to consider and two examples of correctly filled-out calendars. To assess the subjective interpretation the interviewer asked respondents to indicate with an orange marker directly on the calendar sheet the periods during which they felt most vulnerable (also defined as fragile or difficult periods) and with a yellow marker the periods they considered the happiest. This procedure collected important data about respondents' perceptions of their vulnerability.

Figure 3 shows the year count of vulnerable periods by age groups. It reveals some interesting patterns. Two distinct profiles emerge.

Respondents aged 85 and older frequently indicated vulnerable periods during their childhoods and early adulthoods which coincided with the Second World War. That period represented a peak of vulnerability with $12 \%$ of the 85 -andolder respondents reporting experiences of vulnerability. Their vulnerability curve drastically decreased after the war and stayed more or less constant until an increment in reported vulnerability in the most recent 10 years which in this subsample corresponded to their entry into older age-i.e. 60-70 years.

The second group consisting of people younger than 85 years had a less marked profile of vulnerable periods. For all four subgroups the percentage of respondents

\footnotetext{
${ }^{3} \mathrm{VLV}$ is the third of a set of transversal studies on conditions of the elderly population in Switzerland. The first one was conducted in 1979, and the second in 1994 (Lalive d'Epinay et al. 1999).
} 


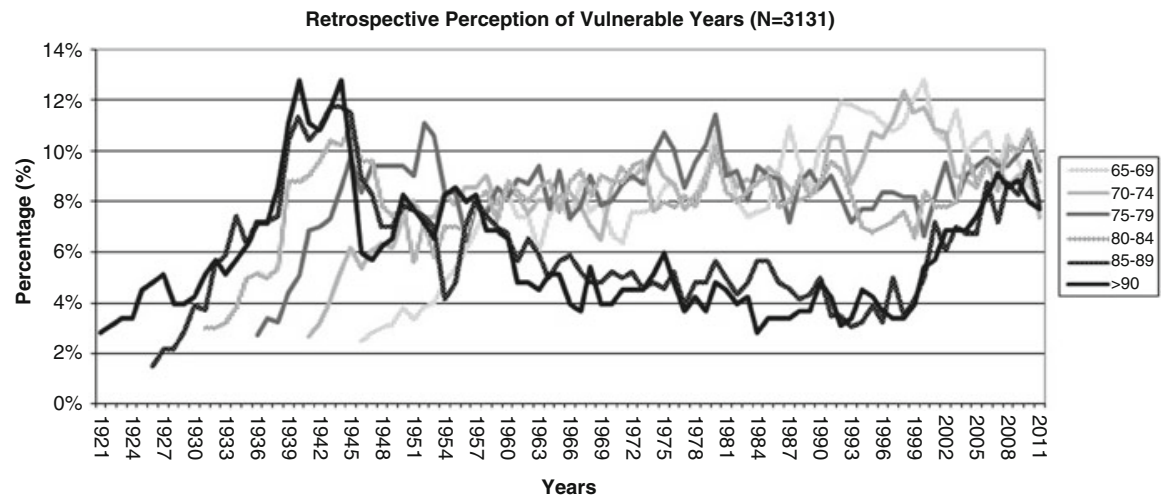

Fig. 3 Percentages of respondents by age groups marking vulnerable years in the VLV survey

reporting vulnerability during childhood was low and especially lower for those 65-69 years old born after the end of the war. However all the groups converged in reporting experienced vulnerability in the 1950s. Therefore while vulnerability was less frequent than in the $85+$ group in the following years it held constant at about 8-9 \% in the younger group. All groups converged again in the most recent years.

The data also showed multiple response patterns reflecting different ways respondents understood or perceived vulnerability. Approximately $46 \%$ of the respondents indicated only one period during which they felt particularly vulnerable followed by $20 \%$ with two and $11 \%$ with three periods. Long periods of vulnerability running through a major part of life were the exceptions: the periods tended to be short (less than 10 years) and got shorter when participants mentioned multiple periods.

The data showed multiple styles of reporting vulnerability. For instance some respondents reported vulnerability as a single enduring experience which covered several years. Some others reported instead recurring vulnerability experiences of shorter length. Similarly the correlation between vulnerability and happy periods was not monotonic. Some reported happiness as opposed to vulnerability while some others superposed periods of happiness and vulnerability to some extent. The combination of these different reporting styles returned a detailed picture of individual interpretations of life trajectories vis-à-vis normative expectations and social contexts. Two examples from the VLV survey may better illustrate these aspects.

The first is the story of "Felicja" (fictional name) a 78-year-old Polish woman living in Geneva. She marked only one period of vulnerability which started at her birth in 1933 and continued until the age of 19. In the calendar she linked no specific event to this long negative period; however it was likely connected to the historical context and possibly the death of her two brothers in 1945 and 1947. Given the absence of objective information an analytic approach based only on factual data would have most likely skipped or undervalued the link between Felicja's experience and the context. But the story is not finished and it has a happy 


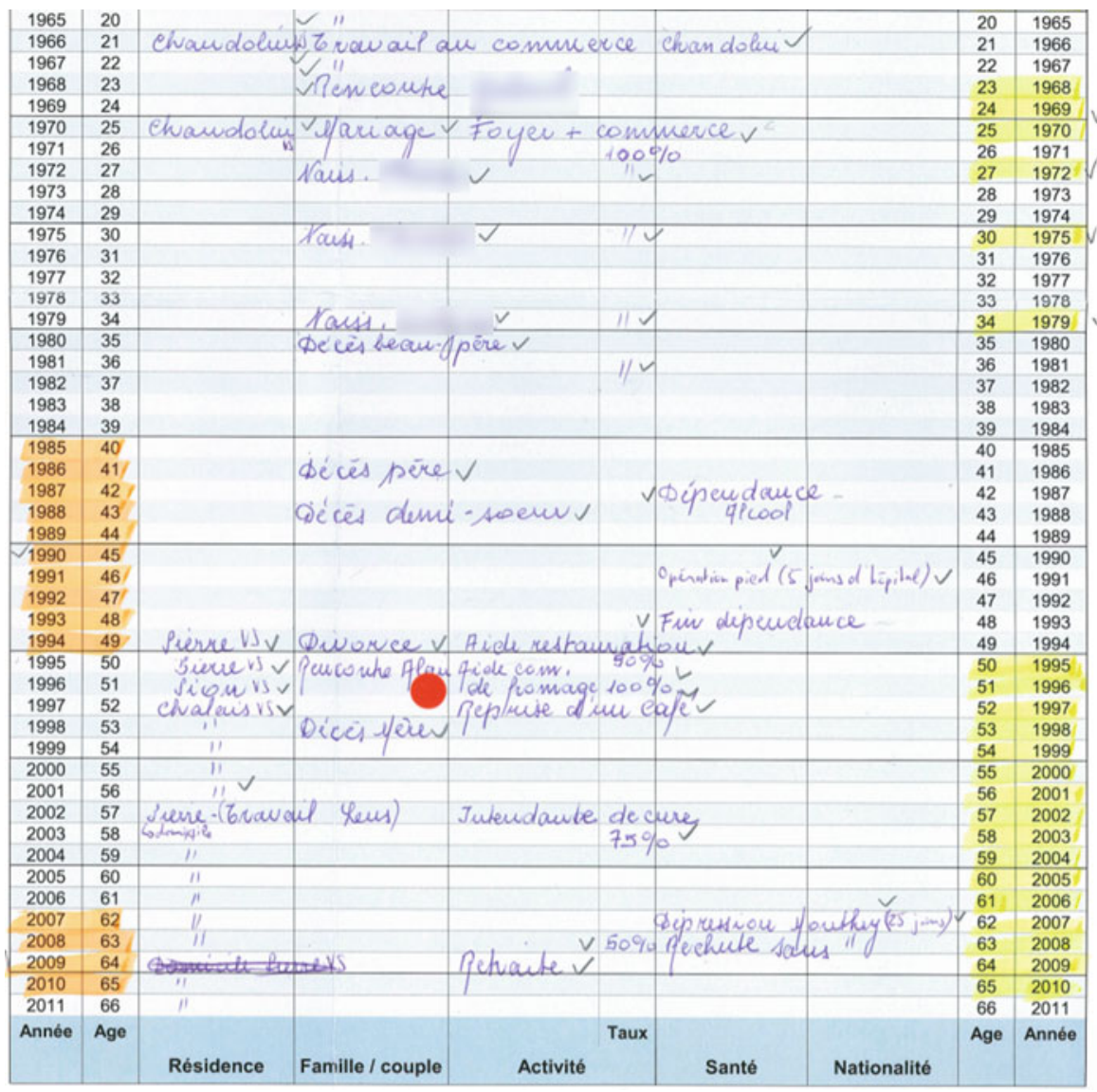

Fig. 4 Adrian's completed Vivre/Leben/Vivere calendar. The orange marks on the left indicate the most vulnerable periods; the yellow marks on the right the happiest ones

ending. Besides this single vulnerable period Felicja indicated one single happy period that started at the age of 30 in 1963 and persisted to the time of the interview when she was 78 years old. In contrast to the blurred edges of the vulnerable period the happy one started with the birth of her daughter in 1963. What is also interesting is that neither the loss of her father in 1979, her divorce in 1981, or the death of her mother in 1982 affected her positive evaluation of life since her daughter's birth.

In contrast with Felicja's style of experiencing and reporting vulnerability Adrian (fictional name) a 66-year-old man from the Valais Canton marked multiple episodes of vulnerability and happiness which seemed to be linked to specific events (Fig. 4). Adrian's most vulnerable period of life started in 19851 year before the loss of his father and continued with the loss of his half-sister in 1989 until his divorce in 1994. In addition the loss of his father had very likely triggered a phase of alcoholism indicated in the health section of the calendar. Before this 10-year period 
of great difficulties Adrian reported positive periods in connection to particular events such as the completion of his education in 1963 meeting his partner in 1968 and the birth of his children in 1972 and 1975. In addition after his divorce in 1994 Adrian marked the beginning of a long period of happiness which was ongoing at the time of the interview despite other difficulties including sinking into a depression a few years before his retirement.

The subjective evaluations in Felicja and Adrian's LHCs add an extra dimension to the analysis that is pivotal for studying vulnerability. Subjective data enables an estimation of the way Felicja and Adrian counterbalanced hard periods or negative events. Felicja's parenting experience and Adrian's new relationship were used $a$ posteriori by the two respondents to cope with common difficult life periods (e.g. bereavement illness transitions).

The assessment of subjective evaluation implemented in VLV thus augments the study of vulnerability adding new value to the interpretation and analyses of LHC data. However the questionnaire asked respondents to provide judgments on their general life conditions (in terms of happiness and vulnerability). In some cases people could feel particularly vulnerable in one specific life domain but not in others.

To overcome this limitation researchers designed a different tool for the assessment of subjective evaluation to implement in the third cohort sample of the Swiss Household Panel (SHP-III). Instead of focusing on the overall evaluation of life the idea behind the Swiss Panel LIVES Calendar (Morselli et al. 2012) was to capture respondents' evaluations of different life spheres separately with the aim of pinpointing spill-over effects. Thus the Swiss Panel LIVES Calendar asked respondents to divide three life domains (couple relationship family life and activity) into periods of different length. The respondents could freely determine the length of the periods. Thus period and events did not necessarily overlap. For instance one may get married once (event) but the marriage can have different phases (periods) with ups and downs. Once respondents had completed the task of sub-setting the three life domains into periods the researchers asked them to express a present-state evaluation for each period on a 5-point bipolar scale ranging from very negative to very positive.

In addition to the considerations drawn from Felicja's and Adrian's LHC this method makes it possible to capture with more precision the counterbalancing between evaluations of one life sphere (e.g. family) and what respondents experienced or perceived in the others (e.g. health job and so on). Moreover by asking respondents to divide the whole trajectory into periods that might not be linked to the specific events asked in the calendar (e.g. residential moves jobs births) this method is particularly suitable for tapping extra information that would otherwise be lost especially when researchers use LHCs to collect highly standardized data.

For instance young respondents' calendars on cohabitation and family events risk having little information compared to older respondents given their shorter life histories. Youths are likely to live with their parents not to have experienced changes in civil-status not to have had children and are not yet inserted into the labour market. The division of life domains into periods makes it possible to detect 
easily and quickly if and when things got better or worse within each life domain even in the absence of specific events. For instance the respondents may report little factual data in the family trajectory but researchers or respondents could divide the family history into periods of relative happiness and periods of conflict.

A limitation of this approach is that it shows that something happened within the trajectory and has changed the evaluation but it is not always possible to explain what happened and why the evaluation changed. All of the examples reported in this chapter proposed complementary tools for the use of LHC in surveying vulnerability. The best solution would be to implement all the specificities of each example into a single tool. Unfortunately this is not always possible in surveys and research requires compromises regarding costs administration times and questionnaire length. Nevertheless the use of one or more of these tools may produce rich data for understanding vulnerability dynamics and processes.

\section{Is It Gold or Just Glittering?}

So far we have made the case for implementing LHCs in research on vulnerability. However all that glitters is not gold and the LHC method has also a number of drawbacks that researchers must consider. Time and costs are problems of the LHC technique (Belli 1998) especially when the calendar has open answers that must be manually entered into a database and eventually coded. However the use of new technologies like tablets may overcome part of these problems and drastically reduce the costs (e.g. Glasner 2011).

More problematic are the administration time and the relative difficulty of the task. Both can easily increase for complex and atypical trajectories but vulnerable populations are the most likely to have complex atypical trajectories that do not follow normative transitions. Thus difficulties in filling LHCs could add to other problematic aspects of surveying vulnerable populations in particular those with low personal resources such as low socio-economic status or low cultural capital. Though the concept of life history calendars is becoming more popular thanks to its implantation on recreational platforms (e.g. Facebook Timelines) filling a calendarbased questionnaire is a cognitively demanding operation.

On the one side we showed that LHCs are suitable to study vulnerability processes from different perspectives considering vulnerability as the interrelation between diffusion accumulation and interpretation processes. By allowing for integrated analytical approaches the LHC can stimulate researchers towards complex and multifaceted understandings of vulnerability interconnecting subjective evaluations with factual episodes. On the other side specific segments of the society especially those at the margin that may be more at risk of experiencing prolonged vulnerability may encounter more difficulties in filling calendar-based questionnaires. Thus researchers should take extreme care in designing questionnaires for potentially vulnerable populations. 
The visual potential of LHCs is still underexplored. LHCs are particularly useful for visualizing and structuring an individual's life trajectory. The graphical layout helps respondents access different types of memory allowing them to change correct and fill gaps during the interview. We showed that the cognitive testing confirmed that certain individuals (but not all) use the calendar in a synchronic way. The calendar's format allows those people to correct the reported information and enhance the reliability of data. Capitalizing on these considerations researchers could enhance the graphical layout of LHCs exploring for instance whether different graphical solutions could help respondents understand and more easily report events in LHCs. If it is not possible to lighten the cognitive task of memory recollection it could be at least made easier by means of graphical and multimedia tricks. Similarly the use of web-based LHCs still needs exhaustive experimentation and may be able to help some categories of respondents as well as making the task more pleasant and less tiring.

Aside from these aspects another point researchers on vulnerability must consider is the non-linearity and non-normativity of life trajectories under vulnerable conditions. As pre-constructed grids LHCs ask respondents to define their trajectories in standardized ways specifying family connections work activity and inactivity and residential history. Even if researchers could control for the social desirability of their questions, the fact that the LHC asks only some information and not others may return to the respondents an unwanted normative message indicating the "important" aspects of life. Thus, the construction of LHCs for surveying vulnerability should allow accounting for unexpected non-normative events and non-typical trajectories. Researchers should seek the right balance between standardization and unexpected types of transition. Recording non-normative events in the Family tiMes LHC as well as the assessments of subjective interpretations in VLV and the Swiss Panel LIVES Calendar were attempts to address this delicate point.

Another aspect worth considering is the role of interviewers vis-à-vis the high variability of how respondents fill in the calendar. Research so far has been inconclusive on the size and likelihood of interviewer effects in LHCs with general population respondents. Belli et al. (2007) did not find any difference in the interviewer variance between LHCs and conventional questionnaires while Sayles et al. (2010) reported a small increase in the interviewer variance for life calendar methods when compared to standardized questionnaires. Morselli et al. (2012) found the interviewer effect was not negligible in face-to-face interviews but was reduced when respondents filled out the LHCs themselves and the interviewer followed a standardized protocol to help them with the task.

Careful training of interviewers should be part of research plans for studies using LHCs. Aside from the interaction with the respondent during the interview, interviewers should also learn how to check the calendar once the respondents have filled them out and to verify with the respondent the exactness of the information.

Despite these aspects that require consideration especially in the design of largescale surveys, the richness and complexity of data produced by LHCs may be worth the drawbacks. LHCs are able to capture essential dimensions of vulnerability accounting for the complex multidimensional time-related processes of individual lives. 
Open Access This chapter is licensed under the terms of the Creative Commons AttributionNonCommercial 2.5 International License (http://creativecommons.org/licenses/by-nc/2.5/), which permits any noncommercial use, sharing, adaptation, distribution and reproduction in any medium or format, as long as you give appropriate credit to the original author(s) and the source, provide a link to the Creative Commons license and indicate if changes were made.

The images or other third party material in this chapter are included in the chapter's Creative Commons license, unless indicated otherwise in a credit line to the material. If material is not included in the chapter's Creative Commons license and your intended use is not permitted by statutory regulation or exceeds the permitted use, you will need to obtain permission directly from the copyright holder.

\section{References}

Antoine, P., \& Lelievre, E. (2009). Fuzzy states and complex trajectories: Observation, modelization and interpretation of life histories. Paris: Institut national d'études démographiques.

Auriat, N. (1993). "My Wife Knows Best": A comparison of event dating accuracy between the wife, the husband, the couple, and the Belgium population register. Public Opinion Quarterly, 57(2), 165-190.

Auriat, N. (1996). Les défaillances de la mémoire humaine. Paris: Presses Universitaires de France, INED.

Axinn, W. G., Pearce, L. D., \& Ghimire, D. (1999). Innovations in life history calendar applications. Social Science Research, 28(3), 243-264.

Axinn, W. G., \& Barber, J. S. (2001). Mass education and fertility transition. American Sociological Review, 481-505.

Beck, U. (1992). Risk society: Towards a new modernity. London: Sage Publications.

Becker, S., \& Sosa, D. (1992). An experiment using a month-by-month calendar in a family planning survey in Costa Rica. Studies in Family Planning, 23, 386-391.

Belli, R. F. (1998). The structure of autobiographical memory and the event history calendar: Potential improvements in the quality of retrospective reports in surveys. Memory, 6(4), 383-406.

Belli, R. F., Schuman, H., \& Jackson, B. (1997). Autobiographical misremembering: John Dean is not alone. Applied Cognitive Psychology, 11, 187-209.

Belli, R. F., Shay, W., \& Stafford, F. (2001). Event history calendars and question-list surveys: A direct comparison of interviewing methods. Public Opinion Quarterly, 65, 45-74.

Belli, R. F., Smith, L. M., Andreski, P. M., \& Agrawal, S. (2007). Methodological comparisons between CATI event history calendar and standardized conventional questionnaire instruments. Public Opinion Quarterly, 71(4), 603-622.

Bertaux, D. (Ed.). (1981). Biography and society: The life history approach in the social sciences. London: Sage.

Bidard, C. (2010). Bifurcations biographiques et ingrédients de l'action. In M. Bessin, C. Bidard, \& M. Grossetti (Eds.), Bifurcations: Les sciences sociales face aux ruptures et à l'événement (pp. 224-238). Paris: La Découverte.

Bourdieu, P. (1979). La distinction. Critique social du jugement. Paris: Editions de Minuit.

Bruner, J. S. (1990). Acts of meaning. Cambridge: Harvard University Press.

Bruner, J., \& Weisser, S. (1991). The invention of self: Autobiography and its forms. Literacy and Orality, 129-148. 
Caspi, A., Moffitt, T. E., Thornton, A., Freedman, D., Amell, J. W., Harrington, H., Smeijers, J., \& Silva, P. A. (1996). The LHC: A research and clinical assessment method for collecting retrospective event-history data. International Journal of Methods in Psychiatric Research, 6, $101-114$.

Coenen-Huther, J. (1994). La mémoire familiale: un travail de reconstruction du passé. Paris: Editions L'Harmattan.

Conway, M. A. (1992). A structural model of autobiographical memory. In M. A. Conway, D. Rubin, H. Spinnler, \& W. A. Wagenaar (Eds.), Theoretical perspectives on autobiographical memory. Dordrecht: Kluwer Academic Publishers.

Conway, M. A. (1996). Autobiographical knowledge and autobiographical memories. In D. Rubin (Ed.), Remembering our past: Studies in autobiographical memory. Cambridge: Cambridge University Press.

Couppié, T., \& Demaziere, D. (1995). Se souvenir de son passé professionnel: Appel à la mémoire dans les enquêtes rétrospectives et construction sociale des données. Bulletin de Méthodologie Sociologique, 49, 23-57.

Crouch, C. (1999). Social change in western Europe. Oxford: Oxford University Press.

Dannefer, D. (2003). Cumulative advantage/disadvantage and the life course: Cross-fertilizing age and social science theory. Journal of Gerontology, 58, 327-337.

Dannefer, D. (2009). Stability, homogeneity, agency: Cumulative dis/advantage and problems of theory. Swiss Journal of Sociology, 35, 193-210.

Eco, U. (1984). The role of the reader: Explorations in the semiotics of texts. Bloomington: Indiana University Press.

Engel, L. S., Keifer, M. C., \& Zahm, S. H. (2001a). Comparison of a traditional questionnaire with an icon/calendar based questionnaire to assess occupational history. American Journal of Industrial Medicine, 40, 502-511.

Engel, L., Keifer, M., Thompson, M. L., \& Zahm, S. (2001b). Test-retest reliability of an icon/calendar-based questionnaire used to assess occupational history. American Journal of Industrial Medicine, 40, 512-522.

Fisher, W. P. (2004). Meaning and method in the social sciences. Human Studies, 27, 429-454.

Freedman, D., Thornton, A., Camburn, D., Alwin, D., \& Young-DeMarcco, L. (1988). The LHC: A technique for collecting retrospective data. Sociological Methodology, 18, 37-68.

Gadamer, H.-G. (1975). Truth and method. New York: Seabury Press.

Glasner, T.J. (2011). Reconstructing event histories in standardized survey research: Cognitive mechanisms and aided recall techniques. Unpublished doctoral dissertation, Vrije Universiteit, Amsterdam.

Goldman, N., Moreno, L., \& Westoff, C. F. (1989). Collection of survey data on contraception: An evaluation of an experiment in Peru. Studies in Family Planning, 20, 147-157.

Halbwachs, M. (1994[1925]). Les cadres sociaux de la mémoire. Paris: Albin Michel.

Hill, R. (1958). Generic features of families under stress. Social Casework, 39, 139-150.

Lalive d'Epinay, L., Bickel, J.-F., Maystre, C., \& Vollenwyer, N. (1999). Vieillesses au fil du temps, 1979-1994: Une révolution tranquille: Santé, situations de vie, formes de participation et visions du monde des personnes âgées en Suisse. Lausanne: Réalités sociales.

Le Goff, J.-M. (2005). Articulation entre la vie familiale et la vie professionnelle. In J.-M. Le Goff, C. Sauvain-Dugerdil, C. Rossier, \& J. Coenen-Huther (Eds.), Maternité et parcours de vie. L'enfant a-t-il toujours une place dans les projets des femmes en Suisse? (pp. 239-277). Berne: Peter Lang.

Le Goff, J.-M. \& Levy, R. (2011). Enquête Devenir parent. Rapport technique. Pavie Working Paper, 11.2.

Levy, R., Ghisletta, P., Le Goff, J.-M., Spini, D., \& Widmer, E. (2005). Incitations for interdisciplinarity in life course research. In R. Levy, P. Ghisletta, J.-M. Le Goff, D. Spini, \& E. Widmer (Eds.), Towards an interdisciplinary perspective on the life course (pp. 361-391). AmsterdamBoston: Elsevier. 
Morselli, D., Roberts, C., Brändle, K., Dasoki, N., Mugnari, E., \& Spini, D. (2012). Self- and interviewer-administered life history calendars. Paper presented at the Eucconet/Society for Longitudinal and Life Course Studies International Conference, 29-31 Oct 2012.

Mortimer, J. T., \& Shanahan, M. J. (2003). Handbook of the life course. New York: Springer.

OFS. (2008). Les familles en Suisse. Rapport statistique 2008. Neuchâtel.

Oesch, D., \& Lipps, O. (2012). Does unemployment hurt less if there is more of it around? A panel analysis of life satisfaction in Germany and Switzerland. European Sociological Review.

Ranci, C. (2010). Social vulnerability in Europe. In C. Ranci (Ed.), Social vulnerability in Europe: The new configuration of social risks (pp. 3-24). Basingstoke: Palgrave Macmillan.

Ranci, C., \& Magliavacca, M. (2010). Social vulnerability: A multidimensional analysis. In C. Ranci (Ed.), Social vulnerability in Europe: The new configuration of social risks (pp. 219249). Basingstoke: Palgrave Macmillan.

Reimer, M. (2001). Die Zuverlässigkeit des autobiographischen Gedächtnisses und die Validität retrospektiv erhobener Lebensverlaufsdaten. Berlin: Max-Planck-Insitut für Bildungsforschung.

Ricoeur, P. (1985). Temps et récit. Tome: Le temps raconté. Paris: Le Seuil.

Sayles, H., Belli, R. F., \& Serrano, E. (2010). Interviewer variance between event history calendar and conventional questionnaire interviews. Public Opinion Quarterly, 74(1), 140-153.

Schutz, A. (1962). Collected papers. The Hague: Martinus Nijhoff.

Scott, J., \& Alwyn, D. F. (1998). Retrospective vs prospective measurement of life histories in longitudinal research. In J. Z. Giele \& G. H. Elder (Eds.), Methods in life course research. Qualitative and quantitative approaches (pp. 98-127). Thousand Oaks: Sage.

Sennett, R. (2011). The corrosion of character: The personal consequences of work in the new capitalism. New York: WW Norton \& Company.

Sutton, J. E., Bellair, P. E., Kowalski, B. R., Hutcherson, D. T., \& Hutcherson, D. T. (2011). Reliability and validity of prisoner self-reports gathered using the life event calendar method. Journal of Quantitative Criminology, 27, 151-171.

Tourangeau, R., Rips, L. J., \& Rasinski, K. (2000). The psychology of survey response. Cambridge: Cambridge University Press.

Van der Vaart, W. (2004). The timeline as a device to enhance recall in standardized research interviews: A split ballot study. Journal of Official Statistics, 20(2), 301-317.

Vivier, G. (2006). Comment collecter des biographies? De la fiche Ageven aux grilles biographiques, Principes de collecte et Innovations recentes. Population et travail Dynamique et Travail, 119-131.

Widmer, E. (2010). Family configurations: A structural approach to family diversity. Ashgate Publishing, Ltd.

Yoshihama, M., Gillespie, B., Hammock, A. C., Belli, R. F., \& Tolman, R. M. (2005). Does the LHC method facilitate the recall of intimate partner violence? Comparison of two methods of data collection. Social Work Research, 29, 151. 